\title{
Feasibility of Using Recycled Asphalt Pavement Aggregates in Concrete Pavement
}

\author{
Metwally A. Abd Elaty ${ }^{1}$, Mariam F. Ghazy ${ }^{2}$, and Mohamed T. Abo-Elenain ${ }^{3}$ \\ ${ }^{1,2}$ Structural Engineering Dept., Faculty of Engineering, Tanta University, Tanta, Egypt \\ Master's candidate, Faculty of Engineering, Tanta University, Tanta, Egypt \\ ${ }^{1}$ Email: Metwali.abdelatty@f-eng.tanta.edu.eg, ${ }^{2}$ Email: Mariam.ghazy@f-eng.tanta.edu.eg \\ ${ }^{3}$ Email:eng_tahael3513@yahoo.com
}

\begin{abstract}
The feasibility of using concrete containing recycled asphalt pavement (RAP) in concrete pavement applications was evaluated. Recycled asphalt pavement (RAP) is the removed pavement material containing asphalt and aggregate. However, limited researches have been done to examine the potential of incorporating RAP into concrete. Since RAP contains asphalt, it is very likely that the toughness of concrete made with RAP could be improved. An alternative use of RAP is to use it as an aggregate in Portland cement concrete (PCC). Concrete containing $0 \%, 15 \%$ and $30 \%$ of RAP replacement by weight of natural coarse aggregates with different cement content with $\left(250,300\right.$ and $\left.350 \mathrm{~kg} / \mathrm{m}^{3}\right)$ were produced in the laboratory and evaluated for their properties that are relevant to performance of concrete pavements. Mechanical properties of the concrete mainly compressive strength, modulus of elasticity and Poisson's ratio after 28 days were recorded. The test results indicated that, the modulus of elasticity was found to decrease as the RAP content of the concrete increased, due to a decrease in the compressive strength of the concrete. However, these results as RAP were incorporated in the concrete, the resulting of compressive strength to modulus of elasticity and Poisson's ratio for the concrete was reduced as compared with mixes that of a reference concrete without RAP. This indicates that, using a concrete containing RAP could possibly result in improvement in the performance of concrete pavements. Moreover, RAP could be used into Portland cement concrete without any modification to the conventional equipment or procedures.
\end{abstract}

Keywords: Portland cement concrete; Recycled asphalt pavement (RAP); Mechanical properties; Modulus of elasticity; Stress - strain relationships.

\section{Introduction}

The modulus of elasticity of concrete is known to have a major effect on the performance of concrete pavements. Modulus of elasticity of concrete is an important input parameter to the American Association of State Highway Transportation Officials (AASHTO) Mechanistic Empirical Pavement Design Guide. Concrete pavements using concrete with a lower modulus of elasticity would have a lower stress due to the same applied load and thus could have a lower chance of cracking. It was reported that, the percentage of cracked slabs increased with an increase in modulus of elasticity of the concrete [1-4].

The optimal concrete mixture for concrete pavement was not necessarily a concrete with a high flexural strength, but a concrete with a proper combination of low modulus of elasticity, low coefficient of thermal expansion, and adequate flexural strength $[4,5]$.

Every year, more than 100 million tons of RAPS is generated by asphalt pavement rehabilitation and reconstruction. In the process of rehabilitation of roads, huge quantity of RAP will be produced along with some amount of dust entrapped, which causes certain percentage of environmental deterioration. This leads to ecological imbalance of nature. Instead of dumping RAP in to open land, the material should be reused. RAP material is used as substitute of fine aggregates and coarse aggregate after proper milling processes in concrete in order, make project more economical, minimize natural resources consumption and to reduce negative impacts on an environment $[6,7]$.

Recycled asphalt pavement (RAP) is mainly used in three ways, first one is using RAP as an aggregate in asphalt hot mix with original aggregate, and second one is extracting the bitumen from the RAP, then using extracted bitumen and coarse aggregates separately in an asphalt mix and third newly adopted is using RAP as aggregate in concrete [6-9]. 


\section{Aim and Research Significance}

this study is directed to produce a concrete through introducing RAP into Portland cement concrete mixtures. These materials may be suitable for several applications at where low modulus of elasticity is required this of course parallel with the benefits regarding the environmental impact due to the consumption of RAP.

\section{Experimental Program}

Laboratory experiment was carried out to investigate the material characteristics of PCC incorporated with RAP. Recycled asphalt pavement was considered to replace the natural coarse aggregates (crushed limestone) by weight. Modulus of elasticity and Poisson's ratio with and without RAP were evaluated. In addition, Compressive strength tests were employed to evaluate the mechanical properties of hardened concrete after the curing time of 28 days.

\subsection{Materials}

Materials used in this experimental work were obtained from local Egyptian sources.

\section{Cement}

The cement used was Portland cement (CEM-1 $42.5 \mathrm{~N}$ ) obtained by the SWEDY Company and complies with Egyptian standard specification [ESS 4756-1/2013] [10]. The properties of the cement used are illustrated in Table (1).

\section{Water}

Tap water free from impurities was used for mixing and curing the test specimens according to the requirement of the [ECP 203/2018] [11].

Table 1- Physical and Mechanical Properties of the Cement Used

\begin{tabular}{lcc}
\hline Property & $\begin{array}{c}\text { Test } \\
\text { Values }\end{array}$ & $\begin{array}{c}\text { [ESS 4756- } \\
1 / 2013] \text { limits } \\
{[10]}\end{array}$ \\
\hline Specific gravity & 3.15 & - \\
\hline Initial setting time (min) & 90 & $\geq 60$ \\
\hline Final setting time $(\mathrm{min})$ & 300 & $\leq 600$ \\
\hline Standard consistency\% & 28 & - \\
\hline Fineness \% & 5 & $<10$ \\
\hline Soundness $(\mathrm{mm})$ & 3 & $\leq 10$ \\
\hline $\begin{array}{l}\text { Compressive } \\
\text { strength } \\
\left(\mathrm{N} / \mathrm{mm}^{2}\right)\end{array}$ & 25.5 & $\geq 10$ \\
\hline
\end{tabular}

\section{Chemical admixture}

A high range water reducer (Trade name: SikaViscocrete 3425 produced by Sika company for construction- Egypt) was used as superplasticizer (SP) meeting the requirements of [ASTM C494, 2017] [12] type F\&G. it is a brown liquid having a density of approximately $1.08 \mathrm{~kg} /$ liter at room temperature. As recommended by the manufacturer, this admixture was added at $0.5-1.5 \%$ by weight cement.

\section{Fine aggregate}

The fine aggregate used in the experimental program was natural siliceous sand with average gradient area. Its characteristics satisfy the requirements of [ECP 203/2018] [11]. It was clean and free from impurities. The physical and mechanical properties of the sand are shown in Table (2). The grain size distribution curve of the used sand is shown in Figure (1).

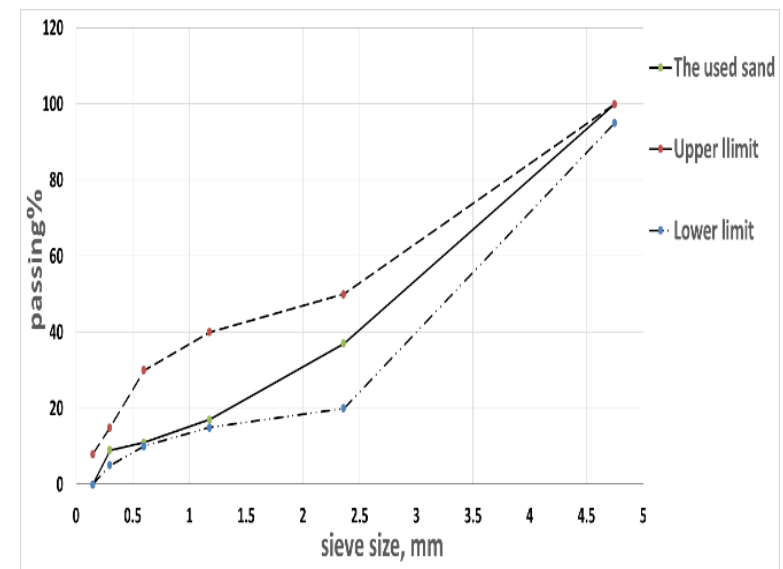

Figure (1)- Grain Size Distribution of the Used Sand [ECP 203-2018 limits] [11]

Table 2- Physical and Mechanical Properties of Sand, Limestone and RAP Used

\begin{tabular}{lccc}
\hline Property & sand & Limestone & RAP \\
\hline $\begin{array}{l}\text { Specific } \\
\text { gravity }\end{array}$ & 2.65 & 2.5 & 2 \\
\hline $\begin{array}{l}\text { Unit weight } \\
\left(\mathrm{t} / \mathrm{m}^{3}\right)\end{array}$ & 1.72 & 1.4 & 1.4 \\
\hline Void ratio (\%) & 35 & 44 & 10 \\
\hline $\begin{array}{l}\text { Fineness } \\
\text { modulus }\end{array}$ & 2.54 & 6.05 & 6.08 \\
\hline $\begin{array}{l}\text { \% clay and } \\
\text { fine matter (by } \\
\text { weight) }\end{array}$ & 2 & 0.5 & 0.2 \\
\hline
\end{tabular}

\section{Coarse aggregate}

The coarse aggregate used was crushed limestone and RAP, which satisfies the requirements [ECP 203/2018] [11]. The specific gravity for limestone and RAP were 2.5 and 2, respectively. The physical and mechanical properties of the crushed limestone and (RAP) are shown in the Table (2). The grain size distribution curve of the used coarse aggregate is shown in Figure (2). 


\section{Metwally A. Abd Elaty, Mariam F. Ghazy, and Mohamed T. Abo-Elenain "Feasibility of Using Recycled Asphalt Pavement Aggregates in Concrete Pavement"}

\subsection{Production of Concrete Mixtures}

The concrete mix proportions with $0 \%, 15 \%$ and $30 \%$ RAP by weight of coarse aggregate were designed for this research study. The cement content was 250 , 300 and $350 \mathrm{~kg} / \mathrm{m}^{3}$ with percentage $(\mathrm{W} / \mathrm{C})$ ratio from 0.49 to 0.57 and $0.5 \% \mathrm{SP}$, with depending on the workability of concrete. Table (3) presents all the concrete mixtures proportions that were evaluated in this research study. The concrete mix proportions are designed by using absolute volume method.

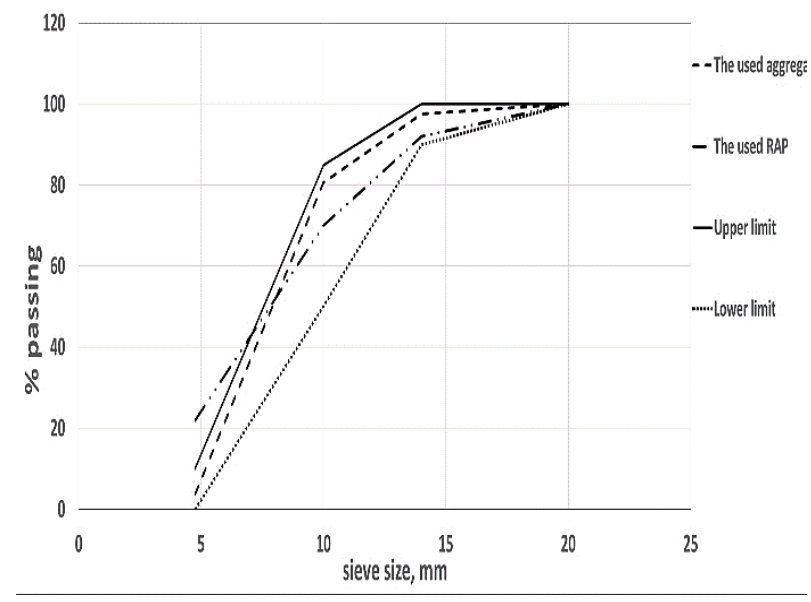

Figure (2)- Limestone and RAP Grading

Table (3)- Concrete Mixes Proportional, $\mathrm{kg} / \mathrm{m}^{3}$

\begin{tabular}{ccccccc}
\hline MIX ID & C & S & CA & RAP & W & SP \\
\hline R0-250 & 250 & 585 & 1170 & 0 & 122.5 & 1.25 \\
\hline R15-250 & 250 & 704 & 1197 & 211 & 122.5 & 1.25 \\
\hline R30-250 & 250 & 585 & 819 & 351 & 122.5 & 1.25 \\
\hline R0-300 & 300 & 598 & 1196 & 0 & 171 & 1.5 \\
\hline R15-300 & 300 & 582 & 989 & 175 & 171 & 1.5 \\
\hline R30-300 & 300 & 568 & 795 & 340 & 171 & 1.5 \\
\hline R0-350 & 350 & 560 & 1120 & 0 & 199.5 & 1.75 \\
\hline R15-350 & 350 & 546 & 928 & 163 & 199.5 & 1.75 \\
\hline R30-350 & 350 & 532 & 745 & 319 & 199.5 & 1.75 \\
\hline
\end{tabular}

Note: C: Cement, S: Sand, SP: Super Plasticizer, W: Water, CA: Crushed limestone aggregate, RAP: Recycled asphalt Pavement.

\subsection{Specimens Preparation and Curing}

The molds were placed on a smooth levelled surface and oil coating was done on the sides of the molds for removal of the specimen from the molds. The concrete was placed in cubes and cylinders mixing molds with compacting; vibrator and then their surfaces were finished using trowel.

- Concrete cubes having the dimensions of 150 x 150 $\mathrm{x} 150 \mathrm{~mm}$ : are used for determining the compressive strength for the investigated mixes at 28 days.

- Concrete cyliders 100 × $200 \mathrm{~mm}$ : are used for determining the modulus of elasticity, Poisson's ratio, and Stress - strain relationships after 28 days.

All the investigated specimens were kept in their molds and covered with plastic sheets for 24 hours in laboratory at temperature $(25 \pm 2){ }^{\circ} \mathrm{C}$ and $50 \% \mathrm{RH}$, then they removed from the molds and remarked with ID's then immerged in clean water at $20{ }^{\circ} \mathrm{C}$ until taken out for testing after 28 days age.

\subsection{Test Proceedings}

Nine mixes were prepared, cast and cured to carry out the tests of compressive strength, Stress-strain relationships and young modulus of elasticity as well as the Poisson's ratio for the test mixtures. For this target, three electrical strain gauges were fixed at the mid height of the cylinders for measuring the average of the vertical and horizontal strains (two vertical and one horizontal strain gauges).

A hydraulic digital compression testing machine controlled by load displacement with total capacities $2000 \mathrm{kN}$ was used for testing specimens in compression in accordance with [ECP 203/2018] [11]. A Universal Testing Machine of $300 \mathrm{kN}$ capacity was used and testing the specimens in accordance with ASTM C 39 [13] for evaluating the modulus of elasticity and the Poisson's ratio. Moreover, a data acquisition system was arranged and connected to the load sensor as well as the strain gages to continuously record the measured data from loading start up to failure. A total of three samples were used for each test, and the resultant data represents the average of the test samples.

\section{Test Results and Discussion}

Table (4) summarizes the average compressive strength [14], modulus of elasticity and Poisson's ratio values of the investigated concrete mixtures at 28 days. The results are also plotted on Figures (3-8).

Table (4)- Concrete Mixes Test Results at 28 Days

\begin{tabular}{lccc}
\hline MIX ID & $\begin{array}{c}\text { Average } \\
\text { Compressive } \\
\text { strength (MPa) }\end{array}$ & $\begin{array}{c}\text { Average } \\
\text { Modulus of } \\
\text { Elasticity } \\
\text { (GPa) }\end{array}$ & $\begin{array}{c}\text { Average } \\
\text { Poisson's } \\
\text { Ratio }\end{array}$ \\
\hline R0-250 & 18 & 17 & 0.25 \\
\hline R15-250 & 15.5 & 11 & 0.26 \\
\hline R30-250 & 14 & 9 & 0.27 \\
\hline R0-300 & 23.5 & 19.7 & 0.23 \\
\hline R15-300 & 18.5 & 14.97 & 0.24 \\
\hline R30-300 & 14.7 & 12.8 & 0.24 \\
\hline R0-350 & 26 & 22 & 0.21 \\
\hline R15-350 & 25 & 17.6 & 0.22 \\
\hline R30-350 & 21 & 13.64 & 0.25 \\
\hline
\end{tabular}




\section{Metwally A. Abd Elaty, Mariam F. Ghazy, and Mohamed T. Abo-Elenain "Feasibility of Using Recycled Asphalt Pavement Aggregates in Concrete Pavement"}

\subsection{Compressive Strength}

The effect of using different cement contents of 250 , 300 , and $350 \mathrm{~kg} / \mathrm{m}^{3}$ on the compressive strength were studied through the investigated mixes R0-250, R0300 and $\mathrm{R} 0-350$, the results were $(18,23.5$ and 26 $\mathrm{MPa}$ ), respectively. It is observed that, the compressive strength of concrete mixes increased with increasing the cement contents. Furthermore, the compressive strength of concrete mixes increased from 18 to $26 \mathrm{MPa}$ with increasing the cement content. Moreover, compressive strength improved by $30.5 \%$ and $44.4 \%$ for mixes R0-300 and R0-350, respectively over the mix R0-250 (mix with cement content $250 \mathrm{~kg} / \mathrm{m}^{3}$ ) (see Figure 3).

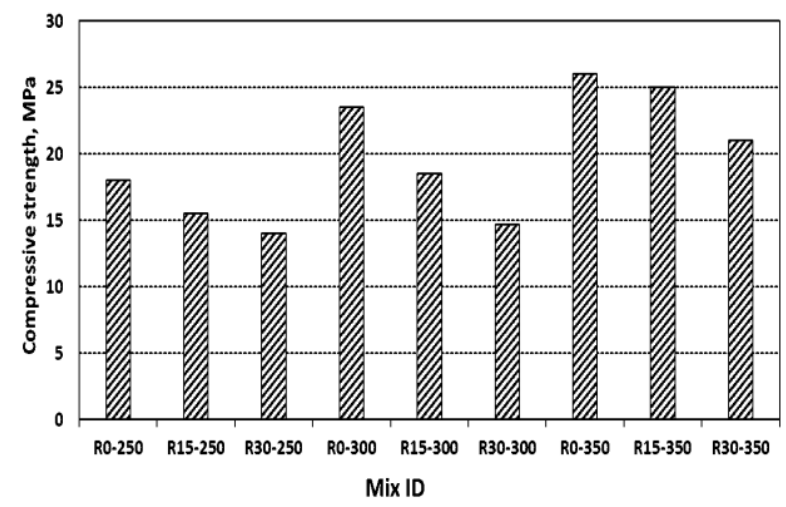

Figure (3)- Test Results of Compressive Strength at 28 Days Age

At cement content $250 \mathrm{~kg} / \mathrm{m}^{3}$, the effect of using RAP at $0 \%, 15 \%$ and $30 \%$ replacement for coarse aggregate was studied through mixes R0-250, R15250 and R30-250, respectively and the results are depicted in Figure (3).

It could be clearly shown that, the compressive strength results for the investigated mixes R0-250, R15-250 and R30-250 were (18, 15.5 and 14) MPa, respectively. The compressive strength of concrete mixes decreased from 18 to $14 \mathrm{MPa}$. Moreover, the compressive strength decreased by $13.8 \%$ and $22.2 \%$ for mixes R15-250 and R30-250, respectively compared to the reference mix R0-250 (mix without RAP).

With cement content $300 \mathrm{~kg} / \mathrm{m}^{3}$, the effect of using RAP at $0 \%, 15 \%$ and $30 \%$ replacement for coarse aggregate was studied through mixes R0-300, R15300 and R30-300, respectively after 28 days and the results were $(23.5,18.5$ and 14.7) $\mathrm{MPa}$ as plotted on Figure (3).

It could be concluded from these results that, the compressive strength of the investigated mixes R0300 and R30-300 decreased from 23.5 to $14.7 \mathrm{MPa}$ after 28 days. The compressive strengths results decreased by increased RAP percentages. Moreover, the compressive strength decreased by $21.3 \%$ and
$37.4 \%$ for mixes R15-300 and R30-300, respectively compared to the reference mix R0-300 (mix without RAP).

When $350 \mathrm{~kg} / \mathrm{m}^{3}$ of cement content was used, the effect of using RAP at $0 \%, 15 \%$ and $30 \%$ replacement for coarse aggregate were studied through mixes R0-350, R15-350 and R30-350, respectively the results values were $(26,25$ and 21$)$ MPa as shown in Figure (3). It could be concluded from these results that, the compressive strength of concrete mixes R0-350 and R30-350 decreased from 26 to $21 \mathrm{MPa}$ after 28 days. Moreover, the compressive strength decreased by $3.8 \%$ and $19.2 \%$ for mixes R15-350 and R30-350, respectively compared to the reference mix R0-350 (mix without RAP).

For all the investigated concrete mixtures, it can be obtained from the test results that, there was a reduction in the compressive strength with the increase in the percentage of RAP in the concrete mixtures. Furthermore, for the investigated mixes without RAP, the strength development was much higher than any other mixtures containing RAP.

\subsection{Modulus of Elasticity}

With using $250 \mathrm{~kg} / \mathrm{m}^{3}$ of cement content, the effect of using RAP of $0 \%, 15 \%$ and $30 \%$ replacement for coarse aggregate was studied through mixes R0-250, R15-250 and R30-250, respectively. Moreover, the results values were $(17,11$ and 9) $\mathrm{GPa}$. Whereas, the results are depicted in Figure (4). It could be noticed for the investigated plastic concrete mixes results that, the modulus of elasticity values for concrete mixes R0-250 and R30-250 decreased from 17 to 9 $\mathrm{GPa}$. The modulus of elasticity values decreased by $35.3 \%$ and $47 \%$ for mixes R15-250 and R30-250, respectively compared with mix R0-250 (mix without RAP).

At cement content $300 \mathrm{~kg} / \mathrm{m}^{3}$, the effect of using RAP of $0 \%, 15 \%$ and $30 \%$ replacement for coarse aggregate was studied through mixes R0-300, R15300 and R30-300, respectively. Moreover, the results values were $(19.7,14.97$ and 12.8) GPa. In addition, the results for the investigated concrete mixes are plotted on Figure (4). It could be noticed that, the modulus of elasticity values for the investigated mixes R0-300 and R30-300 decreased from 19.7 to $12.8 \mathrm{GPa}$. The modulus of elasticity values decreased by $24 \%$ and $35 \%$ for mixes R $15-300$ and R30-300, respectively compared with mix R0-300 (mix without RAP).

When $350 \mathrm{~kg} / \mathrm{m}^{3}$ cement content was used, the effect of using RAP of $0 \%, 15 \%$ and $30 \%$ replacement for coarse aggregate by volume was studied through mixes R0-350, R15-350 and R30-350, respectively. Moreover, the results values were $(22,17.6$ and 


\section{Metwally A. Abd Elaty, Mariam F. Ghazy, and Mohamed T. Abo-Elenain "Feasibility of Using Recycled Asphalt Pavement Aggregates in Concrete Pavement"}

13.64) GPa. In addition, the results for the investigated concrete mixes are depicted in Figure (4). It could be recorded that, the modulus of elasticity values for plastic concrete mixes R0-350 and R30-350 decreased from 22 to $13.64 \mathrm{GPa}$. The modulus of elasticity values for plastic concrete mixes decreased by 20 and $38 \%$ for mixes R15-350 and $\mathrm{R} 30-350$, respectively, respect to $\operatorname{mix} \mathrm{R} 0-350$ (mix without RAP).

It could be concluded from the results that, for all the investigated concrete mixtures replacing a percentage for coarse aggregate with RAP aggregate reduced the modulus of elasticity values of the investigated mixes. The higher the replacement ratio; the higher the reduction in the modulus of elasticity results values. Moreover, the mixture without RAP indicated the highest results.

On the other hand, the stress -strain relationships with different RAP ratios at cement content 250, 300 and $350 \mathrm{~kg} / \mathrm{m}^{3}$ and are shown in Figures (5-7), respectively. It can be observed from these figures that, the slope of the curve decreases with the increase in stress and thereby shows a lower value of modulus of elasticity of all concrete mixes incorporating RAP.

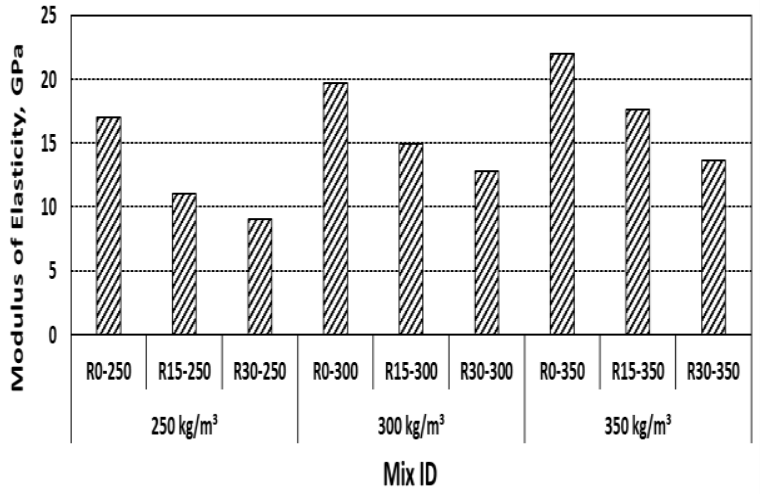

Figure (4)- Modulus of Elasticity at 28 Days Age

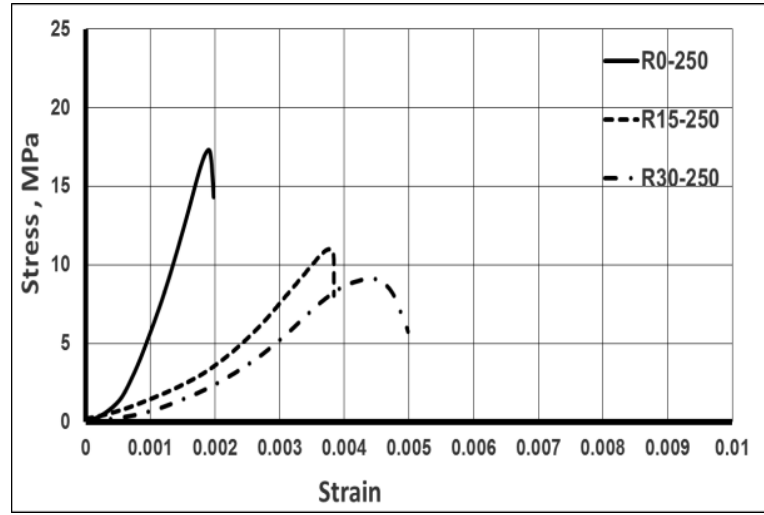

Figure (5)- Stress -Strain Curves for Mixes Containing Cement Content of 250 $\mathrm{kg} / \mathrm{m}^{3}$

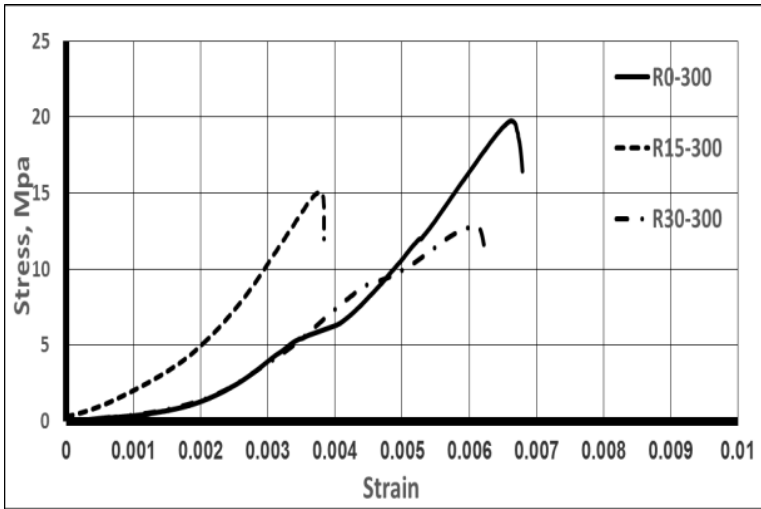

Figure (6)- Stress -Strain Curves for Mixes Containing Cement Content of 300 $\mathrm{kg} / \mathrm{m}^{3}$

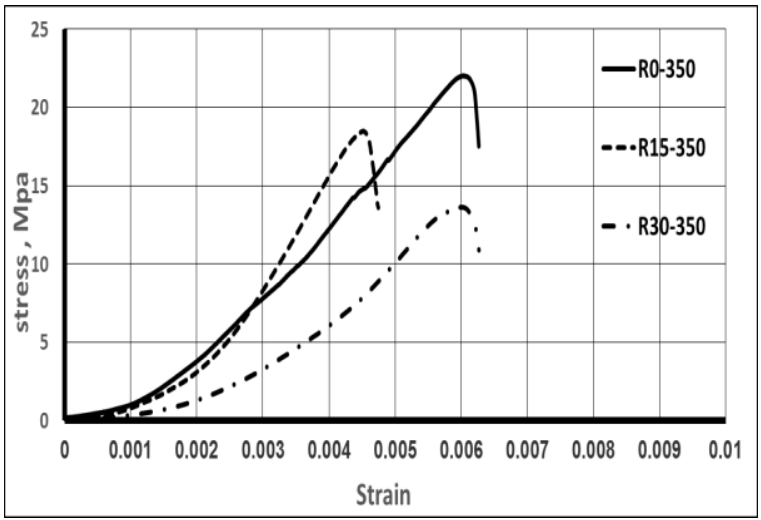

Figure- (7)- Stress -Strain Curves for Mixes Containing Cement Content of $\mathbf{3 5 0}$ $\mathrm{kg} / \mathrm{m}^{3}$

\subsection{Poisson's Ratio}

Table (4) summarizes the test results of Poisson's ratio at 28 days age of the investigated concrete mixtures. Moreover, the results are plotted on Figure (8).

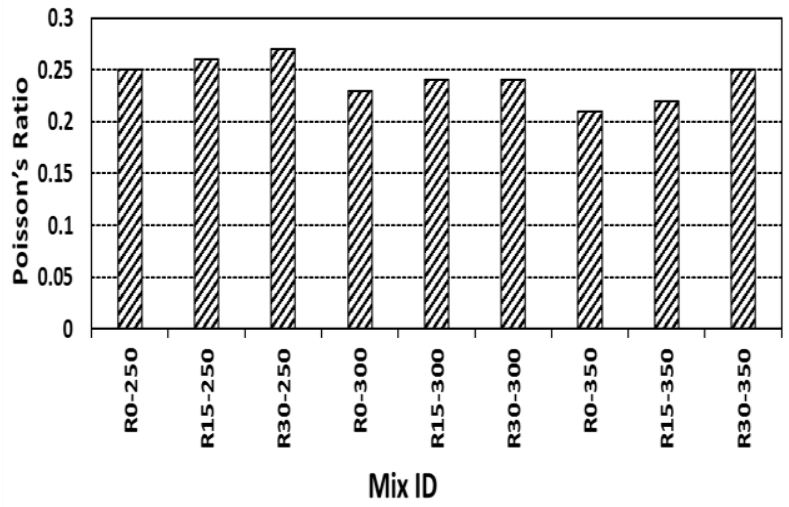

Figure (8)- Test Results of Poisson's Ratio at 28 Days Age 


\section{Metwally A. Abd Elaty, Mariam F. Ghazy, and Mohamed T. Abo-Elenain "Feasibility of Using Recycled Asphalt Pavement Aggregates in Concrete Pavement"}

With using $250 \mathrm{~kg} / \mathrm{m}^{3}$ of cement content, the effect of using RAP of $0 \%, 15 \%$ and $30 \%$ replacement for coarse aggregate was studied through mixes R0-250, R15-250 and R30-250, respectively. It could be noticed for the investigated concrete mixes results that, the results of Poisson's ratio for concrete mixes R0-250 and R30-250 increased from 0.25 to 0.27 . The results of Poisson's ratio values increased by $4 \%$ and $8 \%$ for mixes R15-250 and R30-250, respectively compared with mix R0-250 (mix without RAP).

At cement content $300 \mathrm{~kg} / \mathrm{m}^{3}$, the effect of using RAP of $0 \%, 15 \%$ and $30 \%$ replacement for coarse aggregate was studied through mixes R0-300, R15300 and R30-300, respectively. It could be noticed that, the results of Poisson's ratio for the investigated mixes R0-300 and R30-300 increased from 0.23 to 0.24 . The results of Poisson's ratio increased by the same results $4.3 \%$ for both mixes $\mathrm{R} 15-300$ and $\mathrm{R} 30$ 300, respectively compared with mix R0-300 (mix without RAP).

When $350 \mathrm{~kg} / \mathrm{m}^{3}$ cement content was used, the effect of using RAP of $0 \%, 15 \%$ and $30 \%$ replacement for coarse aggregate by volume was studied through mixes R0-350, R15-350 and R30-350, respectively. It could be recorded that, the results of Poisson's ratio for plastic concrete mixes R0-350 and R30-350 increased from 0.21 to 0.25 . The results of Poisson's ratio for plastic concrete mixes increased by $4.7 \%$ and $19 \%$ for mixes R15-350 and R30-350, respectively, respect to $\operatorname{mix} \mathrm{R} 0-350$ (mix without RAP).

It could be concluded from the results that, for all the investigated plastic concrete mixtures replacing a percentage for coarse aggregate with RAP aggregate by volume increased the results of Poisson's ratio of the investigated mixes. The higher the replacement ratio; the higher in the results of Poisson's ratio. Moreover, the mixture with RAP indicated the highest results.

\section{Conclusions}

From the present study carried out to evaluate the performance of recycled asphalt pavement (RAP) as coarse aggregates in concrete mixture for concrete pavements application, the following main conclusions could be drawn as follows:

1. The results from this study indicated that RAP could be incorporated into Portland cement concrete without any modification to the conventional equipment or procedures to produced concrete mixtures.

2. The inclusion of different cement contents enhanced residual in the cubical compressive strength of concrete mixes. The compressive strength increased with increasing the cement contents for the investigated concrete mixes.

3. Increasing the cement content in concrete mixtures increases the cylindrical modulus of elasticity values.

4. The Poisson's ratio values reduce with increasing cement content. Whereas, the values increase slightly for mixtures containing RAP.

5. The slope of the stress -strain curves decreases with the increase in stress as well as, it shows a lower value of modulus of elasticity of all concrete mixes incorporating RAP.

6. For a specified concrete mix (keeping a fixed cement content), inclusion of RAP enhances remarkably the ductility. Moreover, increasing the RAP volume increases the reduction in the cylindrical modulus of elasticity that makes the mixtures more ductile.

\section{Acknowledgements}

The authors would like to thankfully acknowledge to the staff of the Properties of Material laboratoryFaculty of Engineering- Tanta University for the Help they offered during various stages and the related information used in this study.

\section{References}

[1] AASHTO, American association of state highway and transportation, "Specific gravity and absorption of coarse aggregate standard specification for transportation materials and methods of sampling and testing", 2003.

[2] M. Tia, C.L. Wu, B.E. Ruth, D. Bloomquist, and B. Choubane "Field evaluation of rigid pavement design", Department of Civil Engineering, University of Florida, Gainesville, Florida, USA, 1989, Vol. 1, pp. 50.

[3] M. Tia, D. Bloomquist, G.D. Alungbe, and D. Richardson, "Coefficient of thermal expansion of concrete used in Florida", Department of Civil Engineering, University of Florida, Gainesville, Florida, Vol. 5, 1991, pp. 18-88.

[4] FHWA, Recycled Asphalt Pavement Expert Task Group, "Reclaimed Asphalt Pavement Frequently Asked Questions, Cement and Concrete Research, Vol. 20, 2019, pp. 200-600.

[5] R.J. Collins and S.K.Ciesielski, "Recycling and use of waste materials and by-products in highway construction", NCHRP Synthesis of Highway Practice, Vol. 199, 1994, pp. 92.

[6] B.Huang, X. Shu, and E.G. Burdette, "Mechanical properties of concrete containing recycled asphalt pavement", Magazine of Concrete Research, Vol. 58(5), 2006, pp. 313-320.

[7] Z. Hassan, M. Ali, B. Parastoo and S.Yasha, "The effect of rejuvenators on the aging resistance of 
recycled asphalt mixtures, Construction and Building Materials, Vol. 224, 2019, pp. 89-98

[8] B. Huang, X. Shu and G. Li, "Laboratory Investigation of Portland cement concrete containing recycled asphalt pavements", Cement and Concrete Research, Vol. 35(10), 2005, pp. 2008-2013.

[9] K. Fawaz, A. Edith, G. Lorena and A. Amy, "Performance of asphalt mixtures with high recycled materials content and recycling agents", International Journal of Pavement Engineering, Vol. 21, 2020, pp. 863-877.

[10] ESS 4756-1 (2013), "Egyptian technical specification for composition specification and conformity criteria for common cements", Egyptian Organization for Standardization and Quality Building National Research Center.

[11] ECP 203 (2018), "Egyptian codes for design and construction of building", Appendix Three,
Housing Building National Research Center Egypt.

[12] ASTM C494/C494M-17 (2017), "Standard specification for chemical, admixtures for concrete", ASTM Annual Book of ASTM International Standards, West Conshohocken.

[13] ASTM C 39 (2001), "Standard test method for compressive strength of cylindrical concrete specimens", Annual Book of ASTM International Standards, Vol 03.01, pp. 1-5.

[14] M.A.A. Abd Elaty., M.F. Ghazy, M.T. AboElenain, "Characteristic of cement concrete with recycled asphalt pavement aggregates", International Conference on Advances in Structural and Geotechnical Engineering ICASGE'19, Hurghada, Egypt, Vol. 1, 2019, pp. 1-19. 